Professor Mihai PĂUNICĂ, PhD

E-mail: mihai.paunica@ cig.ase.ro

The Bucharest University of Economic Studies

Professor Alexandru MANOLE, PhD

E-mail: alex@artifex.org.ro

"ARTIFEX" University of Bucharest

Assistant professor Cătălina MOTOFEI, PhD

E-mail: catalina.motofei@ cig.ase.ro

The Bucharest University of Economic Studies

Assistant professor Gabriela - Lidia TĂNASE, PhD

E-mail: gabriela.tanase@ cig.ase.ro

The Bucharest University of Economic Studies

\title{
THE IMPACT OF REMITTANCES ON GDP AND HOUSEHOLD CONSUMPTION. AN EUROPEAN UNION COUNTRIES ANALYSIS
}

\begin{abstract}
Due to the free migration of the labor force in the last years, the level of remittances had increased considerably. The remittances received by a country have an impact on its economy and economic growth. In this context, the present paper studies the effect of remittances received by national economies from the EU28 countries on the Gross Domestic Product and household consumption. The authors aim to measure the causality, in Granger sense, between remittances and Gross Domestic Product (per capita) for the European Union countries, on one hand, and between the remittances and the final consumption of households, on the other hand, for EU28, by using the Toda-Yamamoto approach for Granger causality evaluation, based on VAR models. The results show a positive influence of remittances on GDP only for Italy, Czech Republic, Deutschland and Greece. Influence of remittances on consumption can be confirmed only for the Czech Republic.
\end{abstract}

Keywords: remittances, Gross Domestic Product, consumption, Granger causality, effect.

\section{JEL Classification: F24}

\section{Introduction}

Remittances are not a new phenomenon in the global economy, neither the migration of the labor force. Starting from the context of free circulation of human capital or resources in the European Union area, we believe that migration of the labor force is sizable enough to produce significant remittances for family 
Mihai Păunică, Alexandru Manole, Cătălina Motofei, Gabriela-Lidia Tănase

members, left at home. A study published by the World Bank (Ratha et al., 2016) shows that remittances were expected to increase in 2016, 2017 and 2018. Considering the data presented in the report, from the estimated level of 581.6 US\$ billions in 2015, the indicator might rise to 651.3 US\$ billions in 2018, for the entire world, by an annual rate that is forecasted to reach $4 \%$ in 2018 (increasing from $3.7 \%$ provisioned for 2016).

In this context we can see that remittances are becoming a major financial resource that the national receiving economies should take in to account and properly manage. We considered that remittances may pose a certain influence on the economic development of a country and sought to validate this hypothesis.

International literature presents the multiple influences that remittances exercise on the economy of a country. For the country of origin, the remittances have several effects once received by the beneficiary: on investments, on consumption, on poverty degree or welfare of the receiving household (as reflected in the work of León-Ledesma\&Piracha, 2001), on inequalities in income distribution, on the account deficit (Goschin, 2014), etc. Grigoryev et al. (2014) consider that, in Ukraine, the resource consumption and stability are deeply influenced by the remittances received from abroad. Balan et al. (2014) have analyzed the Moldovan migrants' remittances across the interval 2003-2013, one of the conclusion they drawn was that ' (...) remittances sent by labor migrants to important especially for sustaining consumption income of their families in the home country' (Balan et al., 2014, p. 14).

Based on the influence that remittance may have on a country's economy, this present paper studies the effect of personal remittances received by national economies from UE28 countries for the period 1995-2017 on the Gross Domestic Product and household consumption by using the Toda-Yamamoto approach for Granger causality. We chose to use the Granger causality analysis because it allows us to test the correlation and to analyze the causality (and its direction) between the chosen variables. The test can determine if the lags of a variable contribute to the better estimation of another variable. Unfortunately, the Granger causality has a number of limitations: the direction of the causality depends on the number of lagged included, and the time series must be stationary. To address these problems, we use Toda and Yamamoto's approach of the Granger causality. This method is augmented with extra lags depending on the maximum order of integration, and implies the determination of the maximum order of integration, and the construction of the vector autoregressive model (VAR).

Our research objectives started from the information found in the international literature. For example, Goschin (2014) consider that remittances have an influence on household consumption, but also on investment which will support economic growth. The international literature reports different results regarding the impact of remittances on economic growth. Some studies present a positive relationship, while others a negative one, or no relation between 
The Impact of Remittances on GDP and Household Consumption. An European Union Countries Analysis

remittances and economic growth (see Batu, 2017; Lim \& Simmons, 2015; Goschin, 2014). Lim \& Simmons (2015) analysis regarding the influence of remittances on economic growth in the Caribbean Community and Common Market, shows a long-run influence of remittances on consumption but no evidence regarding a long-run impact on GDP per capita or investment. The authors consider that if remittances are used for investments, then they will support the economic development and that if remittances are used in consumption, the growth will be a short one. But remittances that are used for consumption can also support economic growth indirectly, through the increase of employment and production (Goschin, 2014). Chirila\&Chirila (2017) also state that the influence of remittances on the economy depends on the way there are used. In order to achieve our research objectives, we started from the hypotheses the remittances will influence in a positive manner Gross Domestic Product and household consumption. In order to validate these hypotheses, we collected data from worldbank.org database regarding our three variables, namely GDP per capita, Personal remittances received, Households and NPISHs Final consumption expenditure. The data analysis was performed by using the Toda-Yamamoto approach for Granger causality. The choice for this method (by the TodaYamamoto approach) was driven by the fact that, in the analysis, the levels of the variables can be used, regardless of their order of integration: „even if the processes may be integrated or cointegrated of an arbitrary order" (Toda \& Yamamoto, 1995).The first hypothesis regarding the positive influence of remittances on Gross Domestic Product was confirmed only for 4 out of the $28 \mathrm{EU}$ countries, namely: Italy, Czech Republic, Deutschland and Greece.

The second hypothesis, that analyses the positive impact of remittances on household consumption, is valid only for the Czech Republic.

The paper is structured as follows: literature review, research methodology and data, data analysis, results and discussions, conclusions..

\section{Literature review}

In the context of globalization and free human capital migration, studies regarding remittances gained momentum. Păunică et.al. (2018) have studied the globalization impact on the European Union. The importance of remittances is well recognized in the international literature. Batu (2017) see remittances as a significant source of foreign financing for developing countries and Fromentin (2017) states that remittances are, after foreign direct investment, the largest source of external finance. The importance of remittances relies not only on their value as a financial resource, but also on their influence on various economic factors. Among the main effects of remittances, as mention in the international literature, are included: decrease of inequalities in income distribution, contribution to current account deficit covering (Goschin, 2014).Analyzing all the advantages that 
Mihai Păunică, Alexandru Manole, Cătălina Motofei, Gabriela-Lidia Tănase

remittances may offer, we are tempted to say that they may contribute in this manner to an economic growth. But international studies draw attention to the fact that remittances can also have negative influences. Remittances can generate higher benefits for wealthier families in regard to inequalities in income distribution (Goschin, 2014).Taking into consideration these aspects, we observe that the international literature reports different results regarding the influences of remittances. Howell (2017) addresses the influence of remittances on income inequality for China's rural minority areas, showing that migration increases income for all ethnic groups, but the return to ethnic minority is lower, accentuating the inequality between ethnic groups. Bang et al. (2016) also approach the impact of remittances on income inequality in Kenya. Their findings show that although remittances increase the expenditure of the household, the impact is more significant for poorer households, thus demonstrating that remittances improve poverty and also the income distribution. The authors state that a negative impact of remittances on inequality can be explained by the inequities in the opportunity to migrate.

Same opposite results can also be found regarding the relationship between remittances and financial development. The study performed by Fromentin (2017) on emerging and developing countries, shows that there is a strong, positive long term correlation between remittances and financial development and that, excepting the low-income countries, remittances also have a short term positive influence on financial development. Aggarwal et al. (2011) find a significant and positive connection between remittances and the financial sector development in their study of developing countries. Chowdhury (2011) report a positive significant influence of remittances on financial development in Bangladesh, but no influence of the financial development on the remittances inflow. Coulibaly (2015) report different result regarding the relation between remittances and financial development across Sub-Saharan African countries, concluding that the evidence do not support any bidirectional influence between the two variables.

In this context, of ambiguous results regarding the influence of remittances on different economic variables, we are interested to see what is the general impact of remittances, or their influence on economic growth measured through the GDP, and also on household consumption. The study of Păunică et.al.(2017) reveals the influence of final consumption expenditure of households on the Gross Domestic Product for five countries. Thus, some studies present a positive relationship, while others a negative one, or no relation between remittances and economic growth. Batu (2017) also state that the majority of the international research reports the absence of a link between remittances and economic growth. Lim \& Simmons (2015), and Goschin (2014) also bring in discussion the different result that can be found in the international literature regarding the impact of remittances on economic growth. Stancu and Popescu (2018) conclude that there is a proportional movement of GDP per capita and remittances, thus remittances are a factor that 
The Impact of Remittances on GDP and Household Consumption. An European Union Countries Analysis

influences economic performance. Kumar (2013) found that in Guyana remittances have a significant positive influence on growth in short and long run. Remittances may positively influence economic growth by supporting financial development, by contributing to the formation of the human capital through investment in education, by investment (Bang et al, 2016), etc. In this context is important to analyze the way remittances are being used.

According to the international literature, remittances can be used for consumption or investments. Batu (2017) also argues that temporary remittances have a positive and significant influence on growth rates in GDP per capita, unlike permanent increase of remittances who does not affect growth in GDP. Fromentin (2017) considers that in low income countries, remittances are primarily used for consumption rather than for investments or savings. Lim \& Simmons (2015) analyze the influence of remittances on economic growth in the Caribbean Community and Common Market. Their results show a long-run influence of remittances on consumption but no evidence regarding a long-run impact on GDP per capita or investment. Lim \& Simmons (2015) consider that if remittances are used for investments (in businesses, education, human and physical capital), then they will support the economic development. If remittances are used in consumption, the growth will be a short one. Goschin (2014) consider that remittances have an influence on household consumption, but also on investment which will support economic growth. The author study on Central and Eastern Europe countries revealed a positive and significant impact of remittances on absolute and relative GDP growth.

Chirila\&Chirila (2017) also consider that remittances can contribute to economic development in accordance to the way there are used. Thus, economic growth can be seen when remittances are invested and not only used for consumption or imports. The incentive to invest a part of remittances is influenced by factors such as: basic consumption needs, the characteristics of the economic environment, of the financial market, the interest rates, tax policies, etc. (Goschin, 2014). Remittances that are used for consumption can also support economic growth indirectly, through the increase of employment and production (Goschin, 2014). But the demand increase can also lead to inflation (Goschin, 2014).

In the context of these different views regarding the influence of remittances on GDP and consumption, we analyze the connection between these variables in the UE28 countries by applying the Toda-Yamamoto method for the Granger causality between variables.

\section{Research methodology and data}

The purpose of clustering methods is to group similar elements together. The similarity is established through specific distance metrics, based on which similarity or distance matrix are computer (Aggarwal, 2013). Afterward, 
Mihai Păunică, Alexandru Manole, Cătălina Motofei, Gabriela-Lidia Tănase

clustering algorithms interpret the matrix and create clusters. There are three main clustering methods categories: partitional methods, hierarchical methods and quartet methods.

In order to achieve our research objective (namely to study the effect of personal remittances received by national economies from UE28 countries for the period 1995-2017 on the Gross Domestic Product and household consumption) we used the Toda-Yamamoto approach for Granger causality. There were several missing values (for Malta and Bulgaria), which were not taken into consideration.

Granger causality will allow us to find a pattern of correlation between two variables, and to analyze the causality between them in a time series (https://www.statisticshowto.datasciencecentral.com/granger-causality/).A Granger causality exists between two variables if they have a common trend, thus being cointegrated (Abu-Bader \& Abu-Quarn, 2008). The test for Granger causality is based on the following statement: if past values of a variable improve the forecast (the prediction) of future value of another variable, then the first variable is known to "Granger-cause" the second one (TachiwouAboudou, 2009).

The Granger test is use to determine the direction of the causality (Kumar, 2013). The Granger causality test allows us to determine if the lags of a variable contribute to the better forecasting of another variable (Tekin, 2012). The choice of the lag length is essential due to the fact that the result of the test may be influenced by the lag structure (Coulibaly, 2015). The determination of the optimal lag structure and length is one of the most important steps of the causality test using the Granger method (Tekin, 2012). Choosing the lags depends on the volume of data that are available (https://www.statisticshowto.datasciencecentral. com/granger-causality/).

It's important to know that a first step before using the Granger causality is to make sure that the time series is stationary and to eliminate autocorrelation (https://www.statisticshowto.datasciencecentral.com/granger-causality/).

As TachiwouAboudou (2009)observes, the Granger causality test has a few issues or limits: the direction of the causality depends on the number of the lagged terms that are included, and the variables must be stationary or they must have the same order of integration. The authors bring into discussion the alternative causality test proposed by Toda and Yamamoto that is augmented with extra lags depending on the maximum order of integration. The Toda and Yamamoto method has two major steps: the determination of the maximum order of integration (d max), and the construction of the vector autoregressive model (VAR) taking in to account the optimal number of lagged terms (TachiwouAboudou, 2009). The VAR model allows us to test if lags of any of the variable analyzed Granger-cause any other variable (Kumar, 2013).The Toda-Yamamoto approach for Granger causality allows causality determination between variables that have a different or equal integration order that can be or not co-integrated at a certain rank (Chirila\&Chirila, 2017). This procedure avoids problem such as size and co-integration by 
The Impact of Remittances on GDP and Household Consumption. An European Union Countries Analysis

estimating a vector autoregressive that minimizes the risks that can be related to the incorrect identification of the time series order of integration and the risks cointegration between the variables that are analyzed (Amiri\&Ventelou, 2012). In fact, this approach is based on the estimation of the VAR model that depends on the determination of the maximum integration order for the variables analyzed (which represent a step of the approach), and the determination of the size of the lag for the estimated VAR (Chirila\&Chirila, 2017). The Granger causality and Toda-Yamamoto approach for the Granger causality are largely used in previous studies regarding correlation between variables. For example, Abu-Bader \& AbuQuarn (2008) study the causal relation that can be found between financial development and economic growth, in the particular case of Egypt, within a vector autoregressive through the Granger causality. Amiri\&Ventelou (2012) uses The Toda-Yamamoto approach to analyze the causality between expenditures on health and GDP. TachiwouAboudou (2009) applies a causality test between the development of the stock market and economic growth in order to test the causal relation between the two variables. The Granger non-causality test proposed by Toda and Yamamoto is used to analyze the causal relationships between the GDP growth rate and stock market development measured by two proxies. Tekin (2012) uses the Granger causality analysis to find potential causality among three variables: economic growth (measured through GDP), exports and foreign direct investments.

The Granger causality and the Toda-Yamamoto approach are also used in analysis that implies remittances. Chirila\&Chirila (2017) study the impact of remittances on economic development, investment and export in the particular case of Romania by using the Toda-Yamamoto approach for Granger causality. Their results do not support the statement that remittances will cause the economic development measured by GDP. Coulibaly (2015) investigates, by using the Granger test, the causality link that exists between remittances and financial development in 19 Sub-Saharan African countries, for the period 1980-2010, but they do not find strong evidence to support the connection between the 2 variables in any direction. Kumar (2013) approaches the connection between remittances and economic growth for Guyana, for the period 1982-2010, and find a positive influence of remittances on a short and long term. They use the Granger causality test to determine the elements that cause remittances inflow.

In order to achieve our research objective and study the effect of personal remittances on the Gross Domestic Product and household consumption for the UE28 countries, we also apply the Toda-Yamamoto approach for Granger causality stating form the information found in the international literature.

Our analysis involved two directions: the influence of remittances on GDP and, respectively, on the final consumption of households, by application of Granger causality. 
Mihai Păunică, Alexandru Manole, Cătălina Motofei, Gabriela-Lidia Tănase

The following research hypotheses were formulated:

H1. Remittances do Granger cause Gross Domestic product in the European Union.

H2. Remittances do Granger cause final consumption of households in the European Union.

As stated, the Granger causality between the variables was studied by applying the Toda-Yamamoto method, described in Toda \& Yamamoto (1995). The steps taken by the authors are the following:

a. Determination of the maximum order $\left(o i_{\max }\right)$ of integration between the variables. In order to achieve this, the variables were tested for stationarity with the Augmented Dickey-Fuller and Philips-Perron tests.

b. Estimation on a VAR model between the levels of the variables, using the results of the lag selection test, based on the classical selection criteria.

c. Validation of the VAR model by applying the standard tests for stability and "white noise" residuals;

d. Extension of the lag length of the model with additional $o i_{\text {max }} l a g s ;$

e. Evaluation of Toda-Yamamoto Granger causality by application of the Wald test.

The data were collected from the worldbank.org database, for the countries that are member to the European Union at this time, on three datasets:

- GDP per capita (constant 2010 US\$), indicator code NY.GDP.PCAP.KD. According to the World Bank metadata specification (the definition is included in the data table provided for download), "GDP per capita is gross domestic product divided by midyear population. GDP is the sum of gross value added by all resident producers in the economy plus any product taxes and minus any subsidies not included in the value of the products. It is calculated without making deductions for depreciation of fabricated assets or for depletion and degradation of natural resources. Data are in constant 2010 U.S. dollars.". GDP per capita was considered by the authors as having a greater comparability potential;

- Personal remittances, received (current US\$). The indicator is described in the metadata associated with the data available for download from World Bank online database as "Personal remittances comprise personal transfers and compensation of employees. Personal transfers consist of all current transfers in cash or in kind made or received by resident households to or from nonresident households. Personal transfers thus include all current transfers between resident and nonresident individuals. Compensation of employees refers to the income of border, seasonal, and other short-term workers who are employed in an economy where they are not resident and of residents employed by nonresident entities. Data are the sum of two items defined in the sixth edition of the IMF's Balance of Payments Manual: personal transfers and compensation of employees. Data are in 
The Impact of Remittances on GDP and Household Consumption. An European Union Countries Analysis

current U.S. dollars." The data were deflated by using the GDP deflator, extracted itself, for consistency reasons, from the same data source (World Bank online database).

- Households and NPISHs Final consumption expenditure (constant 2010 US\$). The description for the indicator is the following: "Household final consumption expenditure (formerly private consumption) is the market value of all goods and services, including durable products (such as cars, washing machines, and home computers), purchased by households. It excludes purchases of dwellings but includes imputed rent for owner-occupied dwellings. It also includes payments and fees to governments to obtain permits and licenses. Here, household consumption expenditure includes the expenditures of nonprofit institutions serving households, even when reported separately by the country. Data are in constant 2010 U.S. dollars."

The datasets used in this paper was labeled as last updated on January 30 ${ }^{\text {th }}, 2019$ and include data between 1995 and 2017.

\section{Data analysis, results and discussions}

\subsection{Influence of remittances on the Gross Domestic Product}

The GDP per capita evolution, in the European Union countries, is shown in the figure below:

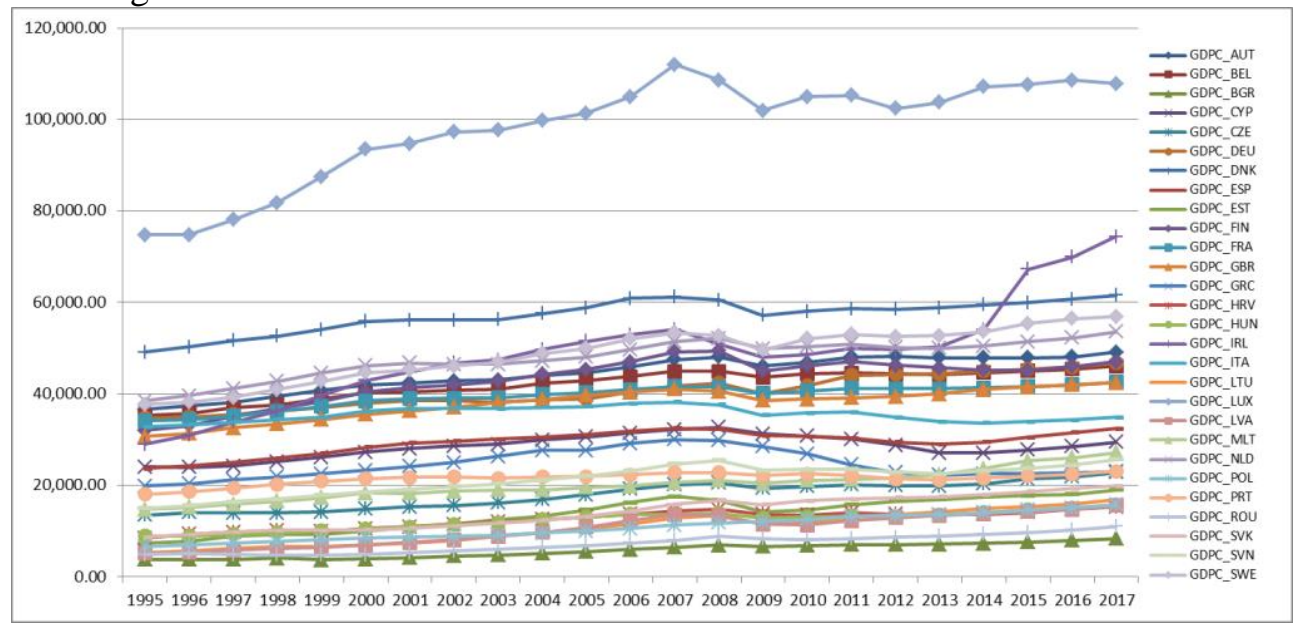

Figure1. Evolution of GDP per capita, EU28 countries, between 1995 and 2017

Source: authors' representation, based on the source data

The observation of the data reveals that Luxembourg is associated with the highest level of GDP per capita. Also, all series display a growth trend over the 23 years. 
The evolution of remittances is displayed in figure 2 .

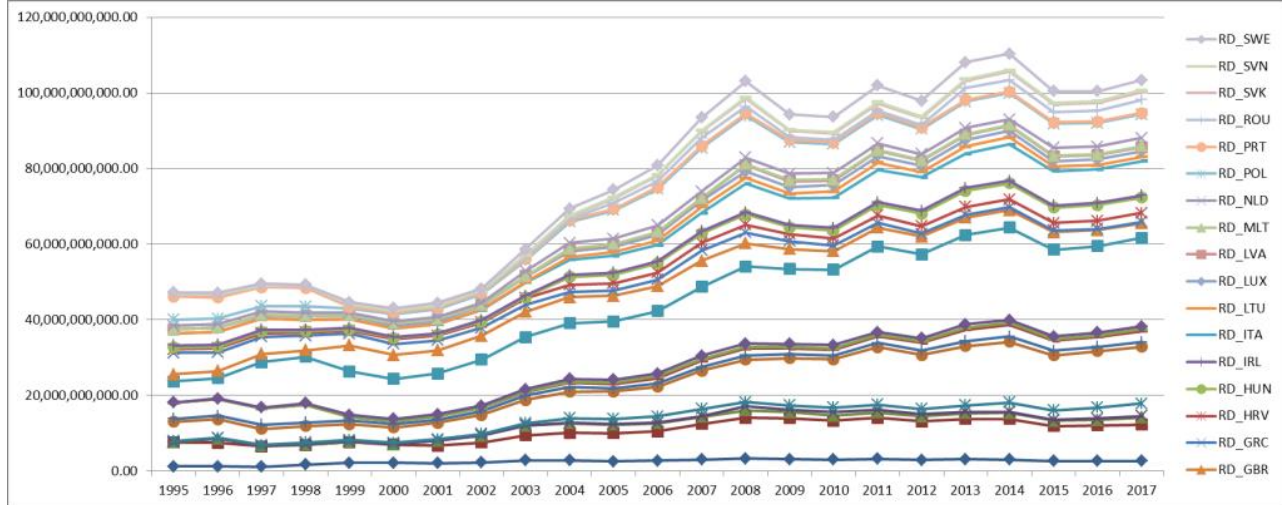

Figure2. Evolution of remittances, EU28 countries, between 1995 and 2017

Source: authors' representation, based on the source data

Overall, the two series display a similar evolution. Also, all datasets for remittances seem to follow close patterns. For almost all countries, there is a trend, visible from 2000 to 2008, after that the remittances drop until 2010, when a recovery is observed and the growth trend continues ever since, but with fluctuations. The drop in 2009 seems to be caused by the effects of the economicfinancial crisis that affected the global economy, including the countries from which remittances flow.

The order of integration for the two variables was evaluated with the Augmented Dickey Fueller - ADF and Philips Perron - PP unit root tests, with the following characteristics:

- For ADF: a maximum of four lags, the variables are supposed to present both intercept and trend, while the Schwarz Information Criterion was employed in the selection between lags. Given the size of the country datasets (23 observations), a maximum of four lags is acceptable, in the opinion of the authors.;

- For Philips Perron: "Exogenous: Constant, Linear Trend, Bandwidth: 6 (Newey-West automatic) using Bartlett kernel".

The significance level chosen for the tests was 5\%. If the two tests provided for conflicting results at the same level of integration (level, $1^{\text {st }}, 2^{\text {nd }}$ or $3^{\text {rd }}$ differences), that is, if one test indicated stationarity and the other did not, the authors have granted trust to the most restrictive result. The maximum order of integration for the Gross Domestic Product and remittances, required by the methodology are presented in the following table: 
The Impact of Remittances on GDP and Household Consumption. An European Union Countries Analysis

Table 1.Maximum order of integration for Gross Domestic Product and remittances variables (oi_max),per country

\begin{tabular}{|c|c|c|c|c|c|c|c|}
\hline Country & AUT & BEL & BGR & CYP & CZE & DEU & DNK \\
\hline oi_max & 1 & 2 & 3 & 2 & 2 & 1 & 2 \\
\hline Country & ESP & EST & FIN & FRA & GBR & GRC & HRV \\
\hline oi_max & 2 & 2 & 1 & 2 & 2 & 2 & 2 \\
\hline Country & HUN & IRL & ITA & LTU & LUX & LVA & MLT \\
\hline oi_max & 2 & 3 & 2 & 2 & 2 & 2 & 2 \\
\hline Country & NLD & POL & PRT & ROU & SVK & SVN & SWE \\
\hline oi_max & 2 & 2 & 2 & 2 & 2 & 2 & 2 \\
\hline
\end{tabular}

Source: authors' processing, based on the source data

To be noted, most of the values are 2. There are three values of 1 (Austria, Germany and Finland), while for Bulgaria and Ireland oi_max is 3.

The next step involves the estimation of VAR models for the levels of data, in the unrestricted form. For each one of countries, the best lag was chosen, from a maximum of three lags (which was appreciated as a reasonable limit, due to the size of the datasets). Where the criteria did not provide the same results, preference was given to the Schwarz Information Criterion (SIC) which, according to Chirilă and Chirilă (2017) "(...) favours models with a reduced number of parameters", which is the case of this study.

The lag lengths $(l)$, chosen according to the specified criteria, for the 28 European Union countries' VAR models that evaluate GDP per capita and remittances, are presented in table no. 2 .

Table 2. Preferred lag lengths, according to Schwarz Information Criteria, for country-specific VAR models

\begin{tabular}{|c|c|c|c|c|c|c|c|}
\hline Country & AUT & BEL & BGR & CYP & CZE & DEU & DNK \\
\hline$l$ & 1 & 1 & 1 & 1 & 1 & 1 & 1 \\
\hline Country & ESP & EST & FIN & FRA & GBR & GRC & HRV \\
\hline$l$ & 2 & 3 & 2 & 1 & 1 & 2 & 2 \\
\hline Country & HUN & IRL & ITA & LTU & LUX & LVA & MLT \\
\hline$l$ & 1 & 1 & 3 & 1 & 1 & 2 & 1 \\
\hline Country & NLD & POL & PRT & ROU & SVK & SVN & SWE \\
\hline$l$ & 1 & 1 & 1 & 1 & 1 & 1 & 1 \\
\hline
\end{tabular}

Source: authors' processing, based on the source data

All VAR models were re-estimated with the lag length specified in the table no. 2. Subsequently, the VAR models were evaluated on the three statistical tests: autocorrelation LM test, normality (Cholesky) and White VAR residual heteroskedasticity tests, with no cross terms (only levels and squares), to ascertain their reliability. In the case of unreliable model specification, additional lags were added to the respective vector autoregressions). Also, the AR roots were verified, 
Mihai Păunică, Alexandru Manole, Cătălina Motofei, Gabriela-Lidia Tănase

to assess the stability of the model. To ensure consistency across the data processing, the confidence level was kept at $5 \%$.

The Belgian model was assessed to be reliable with the original lag length, as well as the models for Bulgaria, Estonia, Finland, Italy, Luxembourg, Latvia, Poland. For the Czech model, the AR roots table displayed warnings on the lack of stability, thus lag length in the original model was raised up to 4. At this level, all other tests were satisfactory, thus the model can be processed in order to check for Granger causality. Germany presented the same issue, therefore the lag length was increased by one unit, to 2 . The results of the autocorrelation test made necessary the inclusion of two additional lags. As all tests provided proper results with these settings, the model was adapted for the proposed methodology.

Likewise, for Spain, Malta, Netherlands, Portugal and Greece, the VARs had to be adjusted at a 4 lag length, while the French and Croatian ones proven to be satisfactory with $l=3$. The Swedish model was set with a lag length of 2 .

Next, the models were re-adjusted by expanding the lag length with the number indicated by oi_max, the new variables being inputted as exogenous in the model. Then, the Wald test was applied, and the results are presented in the following table (only for the cases where VAR tests gave valid coefficients):

Table 3. Result of the VAR Granger Causality/Block Exogeneity Wald Tests for the models with correct specifications

\begin{tabular}{|l|c|c|c|l|c|c|c|}
\hline \multicolumn{1}{|c|}{ Country } & CHI SQ & $d f$ & $p$-value & Country & CHI SQ & $d f$ & $p$-value \\
\hline Belgium & 0.278619 & 1 & 0.5976 & Deutschland & 10.91521 & 4 & 0.0275 \\
\hline Bulgaria & 0.157520 & 1 & 0.6915 & Spain & 5.119369 & 4 & 0.2753 \\
\hline Estonia & 6.120142 & 3 & 0.1059 & Malta & 0.361982 & 4 & 0.9855 \\
\hline Finland & 2.272952 & 2 & 0.3209 & Netherlands & 2.124017 & 4 & 0.7130 \\
\hline Italy & 15.19965 & 3 & 0.0017 & Portugal & 0.432354 & 4 & 0.9797 \\
\hline Luxembourg & 0.576785 & 1 & 0.4476 & Greece & 18.95347 & 4 & 0.0008 \\
\hline Latvia & 2.558690 & 2 & 0.2782 & France & 2.061390 & 3 & 0.5598 \\
\hline Poland & 0.064716 & 1 & 0.7992 & Croatia & 5.363451 & 3 & 0.1470 \\
\hline Czech Rep. & 17.65697 & 4 & 0.0014 & Sweden & 3.345173 & 2 & 0.1878 \\
\hline
\end{tabular}

Source: authors' processing, based on the source data

Only the results corresponding to the scope of the paper are included, that is the ones that specify the GDPC as dependent variable, and the null hypothesis of the test is, in this way, of non-causality between remittances and GDP per capita.

By keeping the 5\% level of significance, the null hypothesis of noncausality can be rejected only for Italy, Czech Republic, Deutschland and Greece. For all these countries, the analysis validates the H1 research hypothesis. For all other countries, the hypothesis does not verify. Not all the VAR models have valid results when tested for consistency. The Austrian model displayed issues with the normality, in all components (Skewness, Kurtosis and Jarque-Berra). By increasing the lag length to 4, the model satisfies the tests, but does not comply with the AR roots criterion. Similarly, in the case of Cyprus, the attempts to correct the model 
The Impact of Remittances on GDP and Household Consumption. An European Union Countries Analysis

had failed because of the insufficient number of observations, same as Denmark, Great Britain, Hungary, Lithuania, Romania, Slovakia, and Slovenia. For these countries, the data were transformed by logarithm, and the methodology was reapplied. The logarithms, which describe the elasticity of the indicators, are proper to be used when evaluating the Granger causality. Following the application of the ADF and PP tests, all $\log (\mathrm{GDPC})$ variables are $\mathrm{I}(2)$. As the variables describing remittances have the same degree of integration, the oi_max factor is 2 for all models. The next stage involves the analysis of the optimum lag length. As in the case of the first set of models, the SIC was the preferred criteria in the case of divergent results. Then, the VAR models were estimated, tested and augmented with the variables corresponding to the oi_max values, and the values of the Wald test were extracted.

Problems were encountered in the case of Lithuania, Slovenia, Slovakia, Denmark and Hungary, similar to the situation described in the previous section. The British model displayed lack of normality in the residuals up to a lag length of 5. For Romania, the Wald test showed a chi-square value of 6.746570, at 4 degrees of freedom. This value indicates that the remittances, in the case of Romania, do not Granger cause GDP per capita.

4.2. Influence of remittances on the final consumption of households

As in the previous section, the first step involved the determination of the maximum order of integration. The same procedure was followed.

Table 4.Maximum order of integration for final consumption and remittances variables, per country

\begin{tabular}{|c|c|c|c|c|c|c|c|}
\hline Country & AUT & BEL & BGR & CYP & CZE & DEU & DNK \\
\hline oi_max & 2 & 2 & 3 & 1 & 2 & 2 & 2 \\
\hline Country & ESP & EST & FIN & FRA & GBR & GRC & HRV \\
\hline oi_max & 2 & 2 & 1 & 2 & 2 & 2 & 2 \\
\hline Country & HUN & IRL & ITA & LTU & LUX & LVA & MLT \\
\hline oi_max & 2 & 3 & 2 & 2 & 2 & 2 & 2 \\
\hline Country & NLD & POL & PRT & ROU & SVK & SVN & SWE \\
\hline oi_max & 2 & 2 & 2 & 2 & 2 & 2 & 2 \\
\hline
\end{tabular}

Source: authors' processing, based on the source data

* PP test provided inconclusive results.

It can be observed that almost for all countries the values of oi_max are 2 . The next step involves the estimation of VARs and the correction of the lag length according to the SIC. The results of the selected lag lengths are presented in the following table: 
Mihai Păunică, Alexandru Manole, Cătălina Motofei, Gabriela-Lidia Tănase

Table 5. Preferred lag lengths, according to Schwarz Information Criteria, for country-specific VAR models

\begin{tabular}{|c|c|c|c|c|c|c|c|}
\hline Country & AUT & BEL & BGR & CYP & CZE & DEU & DNK \\
\hline$l$ & 1 & 1 & 1 & 1 & 1 & 1 & 1 \\
\hline Country & ESP & EST & FIN & FRA & GBR & GRC & HRV \\
\hline$l$ & 2 & 2 & 3 & 1 & 1 & 2 & 1 \\
\hline Country & HUN & IRL & ITA & LTU & LUX & LVA & MLT \\
\hline$l$ & 2 & 1 & 1 & 1 & 1 & 2 & 1 \\
\hline Country & NLD & POL & PRT & ROU & SVK & SVN & SWE \\
\hline$l$ & 1 & 2 & 1 & 1 & 1 & 3 & 1 \\
\hline
\end{tabular}

Source: authors' processing, based on the source data

Following the recalibration of VARs, the four tests for model correctness were applied. Where issues were found, the lag length was increased, as the dataset permitted. Then, additional variables of $l$ up to oi_maxwere added,

For Austria, there were autocorrelation issues for $l$ up to 3. With a lag length of 4 , the model responded well to the tests. The model for Belgium is properly specified with the original $l$. The Bulgarian VAR was set with $l=2$, due to normality issues, which were also encountered in the case of Cyprus, where lag length was increased to 3.

The German model displayed unit root problems up to lag length 3, but all test proven satisfactory when $l$ was set to 4 , as it was the case for Spain (autocorrelation and normality issues), while Denmark's VAR was found to be robust at the initial length, as it was the case with the Estonian, French and Finland ones. As the Greek VAR defended against the specification tests, it was redefined according to the methodology, and its WALD score recorded. For Croatia, the initial model failed to pass the heteroskedasticity test, so $l$ was increased to 2 , and the problem was corrected. The Irish VAR passed the reliability tests with lag length 1, the same situation applied to the Slovak model, and the Luxembourg and Latvian models were properly estimated at the original $l$. For Netherlands, and Portugal, the lag length was increased to 4 , as the lower levels displayed problems with the statistical tests.

At the 5\% significance level, the Slovenian model performs well against all the tests with an $l$ of 3 . The results of the Wald tests are presented in the table 6 .

Table 6. Result of the VAR Granger Causality/Block Exogeneity Wald Tests for the models with correct specifications

\begin{tabular}{|l|l|l|l|l|l|l|l|}
\hline Country & CHI $S Q$ & $d f$ & $p$-value & Country & CHI $S Q$ & $d f$ & $p$-value \\
\hline Austria & 10.84636 & 4 & 0.0283 & Croatia & 3.150641 & 2 & 0.2069 \\
\hline Belgium & 0.006583 & 1 & 0.9353 & Hungary & 0.803271 & 2 & 0.6692 \\
\hline Bulgaria & 0.232442 & 2 & 0.8903 & Ireland & 0.725306 & 1 & 0.3944 \\
\hline Cyprus & 20.47440 & 3 & 0.0001 & Luxembourg & 2.342553 & 1 & 0.1259 \\
\hline Deutschland & 5.548771 & 4 & 0.2355 & Latvia & 0.475833 & 2 & 0.7883 \\
\hline
\end{tabular}


The Impact of Remittances on GDP and Household Consumption. An European Union Countries Analysis

\begin{tabular}{|l|l|l|l|l|l|l|l|}
\hline Denmark & 0.187576 & 1 & 0.6649 & Netherlands & 6.610315 & 4 & 0.1580 \\
\hline Spain & 4.249161 & 4 & 0.3733 & Poland & 1.116582 & 2 & 0.5722 \\
\hline Estonia & 3.798492 & 2 & 0.1497 & Portugal & 1.911847 & 4 & 0.7520 \\
\hline Finland & 2.211979 & 3 & 0.5296 & Slovakia & 0.052048 & 1 & 0.8195 \\
\hline France & 0.369816 & 1 & 0.5431 & Slovenia & 3.263246 & 3 & 0.3528 \\
\hline Greece & 1.155599 & 2 & 0.5611 & & & & \\
\hline
\end{tabular}

Source: authors' processing, based on the source data

The interpretation of the Chi square values in the table no 6 confirm the presence of Granger causality in Austria and Cyprus. In the other countries, the results plead in support of the null hypothesis of the test. When testing the Great Britain VAR between remittances and final consumption, autocorrelation was solved by setting lag length to five. However, the root test indicated that VAR does not satisfy the stability condition. The Italian model displayed issues of nonnormality in residuals at original lag length, up to $l=5$. At this level, the model is affected by serial correlation in the residuals. The Czech, Lithuanian, Romanian and Swedish models failed to pass the at least one of the tests, even with lag length increased to 5.Therefore, the authors have chosen to transform the variables by using logarithm.

Table 7. Order of integration for logarithm final consumption and remittances variables and oi_max, per country

\begin{tabular}{|c|c|c|c|c|c|c|}
\hline Country & CZE & GBR & ITA & LTU & ROU & SWE \\
\hline OI_FC $(\log )$ & 1 & 2 & 2 & 2 & 2 & 1 \\
\hline OI_REM $(\log )$ & 1 & 1 & 1 & 2 & 1 & 2 \\
\hline oi_max & 1 & 2 & 2 & 2 & 2 & 2 \\
\hline
\end{tabular}

Source: authors 'processing, based on the source data

The lag lengths for the six models are presented in table no. 8, chosen upon the SI criterion.

Table 8. Lag length for logarithm-variables VARs

\begin{tabular}{|c|c|c|c|c|c|c|}
\hline Country & CZE & GBR & ITA & LTU & ROU & SWE \\
\hline Lag length & 1 & 1 & 1 & 1 & 1 & 1 \\
\hline
\end{tabular}

Source: authors' processing, based on the source data

The level of significance was retained, 5\%. All models were re-designed according to the lag lengths in table 8 and tested for consistency. The Czech model indicated problems, so the lag length was increased to 2. This configuration responded well to the tests, so the subsequent steps were taken, and the Wald test reveals the existence of Granger causality: remittances Granger cause the final consumption in the Czech Republic. At the original $l$, the British and Lithuanian models show autocorrelation problems. At 5 lags, the problem for GBR is solved, but the new model fails to pass the AR roots stability test. The Lithuanian model still has autocorrelation in residuals. The Italian VAR passes all tests when $l=1$. 
Mihai Păunică, Alexandru Manole, Cătălina Motofei, Gabriela-Lidia Tănase

After processing, the Wald test validates the null hypothesis of no Granger causality by remittances on the final consumption.

For Romania, the model is well specified at 1 lag length. The Wald test, after including the additional lags (according to oi_max shown in Table 7), indicates no Granger causality. The Swedish VAR is consistent with the original setting, and its Wald statistic pleads against Granger causality.Therefore, the only case in which the remittances do Granger cause final consumption is the Czech Republic.

\section{Conclusions}

As the level of remittances grows in the context of free human capital migration in the European Union countries, their influence on a country's welfare can also be observed. According to the international literature, remittances may have an impact on: economic growth, financial development, consumption, investment, income, poverty, inequalities in income distribution, etc. Remittances have an influence on household consumption, but also on investment, which is considered to support economic growth. Starting from the information gathered from the literature review, our research study has two major objectives: to analyze the influence of personal remittances received by national economies from UE28 countries for the period 1995-2017 on the Gross Domestic Product and household consumption by using the Toda-Yamamoto approach for Granger causality.

The Granger causality was used because it allows us to analyze the causality between variables. The test can determine if the lags of a variable contribute to a better estimation of another variable. Because the Granger causality has a number of limitation (the direction of the causality depends on the number of lagged included, and the time series must be stationary), we use Toda and Yamamoto's approach of the Granger causality. Thus we made a determination of the maximum order of integration, and we construct the vector autoregressive model (VAR).The data for the study, namely the values for the three variables (GDP per capita, Personal remittances received, Households and NPISHs Final consumption expenditure) were collected from the worldbank.org database. The data analysis was performed by using the Toda-Yamamoto approach for Granger causality. First, we determined the maximum order $\left(o i_{\max }\right)$ of integration between the variables. Then we realized an estimation on a VAR model between the levels of the variables, using the results of the lag selection test, based on the classical selection criteria. We validated the VAR model by applying the standard tests for stability and "white noise" residuals. As a next step, we extended the lag length of the model with additional $o i_{\max }$ lags. In the final step, we evaluated the TodaYamamoto Granger causality by application of the Wald test.

The results of the study do not support the stated hypothesis. We didn't find a strong influence of remittances on Gross Domestic Product and household consumption for all countries that are a part of EU28. The first hypothesis regarding the positive influence of remittances on Gross Domestic Product was 
The Impact of Remittances on GDP and Household Consumption. An European Union Countries Analysis

valid only for 4 out of the 28 EU countries: Italy, Czech Republic, Deutschland and Greece. The second hypothesis that analyses the positive impact of remittances on household consumption is valid only for the Czech Republic.

Our future research will focus on explaining the lack of impact that remittances have on Gross Domestic Product and household consumption by identifying the possible intermediary factors between the dependent variable and the explanatory factor.

\section{REFERENCES}

[1] Abu-Bader, S., Abu-Qarn, A. S. (2008), Financial Development and Economic Growth: The Egyptian Experience; Journal of Policy Modeling, 30(5): 887-898;

[2] Aggarwal, R., Demirgüç-Kunt, A., MartínezPería, M.S. (2011),Do

Remittances Promote Financial Development?; Journal of Development Economics, 96(2):255-264;

[3] Amiri, A., Ventelou, B.(2012),Granger Causality between Total Expenditure on Health and GDP in OECD: Evidence from the Toda-Yamamoto Approach; Economics Letters, 116(3):541-544;

[4] Balan, C., Jaba, E., Pârțachi, I., Chistrugă, B. (2014),Statistical Analysis of the Seasonal Variation of Moldovan Migrants' Remittances during the Period 2003-2013; Studies and Scientific Researches, Economics Edition, (19):7-16; [5] Bang, J. T., Mitra, A., Wunnava, P.V. (2016), Do Remittances Improve Income Inequality? An Instrumental Variable Quantile Analysis of the Kenyan Case; Economic Modelling, 58: 394-402;

[6] Batu, M. (2017), International Worker Remittances and Economic Growth in a Real Business Cycle Framework; Structural Change and Economic Dynamics, 40: 81-91;

[7] Chirila, V.,Chirila, C. (2017), The Analysis of Romania's External Migration and of the Causality between Remittances and Romania's Economic Growth; Amfiteatru Economic, 19(46): 696-710;

[8] Chowdhury, M.B. (2011), Remittances Flow and Financial Development in Bangladesh; Economic Modelling, 28(6):2600-2608;

[9] Coulibaly, D. (2015), Remittances and Financial Development in Sub-

Saharan African Countries: A System Approach; Economic Modelling, 45: 249258;

[10] Fromentin, V. (2017), The Long-run and Short-Run Impacts of

Remittances on Financial Development in Developing Countries; The Quarterly Review of Economics and Finance; In Press, Corrected Proof, Available online 27 February 2017; 
Mihai Păunică, Alexandru Manole, Cătălina Motofei, Gabriela-Lidia Tănase

[11] Goschin, Z. (2014), Remittances as an Economic Development Factor. Empirical Evidence from the CEE Countries; Procedia Economics and Finance 10:54-60 ;

[12] Grigoryev, L. M., Buryak, E. V.,Golyashev, A.V.(2014), The Second Start of Transformation in Ukraine? ; VoprosyEconomiki, 9;

[13] Howell, A. (2017), Impacts of Migration and Remittances on Ethnic Income Inequality in Rural China ; World Development, 94: 200-211;

[14] Kumar, R.R. (2013),Remittances and Economic Growth: A Study of Guyana; Economic Systems, 37(3): 462-472;

[15] León-Ledesma, M., Piracha, M. (2001), International Migration and the Role of Remittances in Eastern Europe. Retrieved January 20, 2017, from ftp://ftp.ukc.ac.uk/pub/ejr/RePEc/ukc/ukcedp/0113.pdf;

[16] Lim, S., Simmons, W.O. (2015), Do Remittances Promote Economic Growth in the Caribbean Community and Common Market?; Journal of Economics and Business, 77:42-59;

[17] Păunică, M.,Manole, A., Motofei, C., Tănase, G.L. (2018), The Globalization in the actual Context of the European Union Economy; Proceedings of ehe 12th International Conference on Business Excellence, 12(1):739-750, DOI: 10.2478/picbe-2018-0066;

[18] Păunică, M., Manole, A.,Motofei, C. (2017),A Study on the Influence of Final Consumption Expenditure of Households and Foreign Trade on the Gross Domestic Product - Case of Romania and Five European Union Countries with Highest GDP; Vision 2020: Sustainable Economic Development, Innovation Management, and Global Growth; VolsI-IX, pp. 2884-2891;

[19] Ratha,D., Supriyo, D., Plaza, S., Schuettler, K., Shaw, W., Wyss, H., Yi, S. (2016), Migration and Remittances - Recent Developments and Outlook; Migration and Development Brief 26, April 2016, World Bank, Washington, DC. Doi: 10.1596/ 978-1-4648-0913-2 License: Creative Commons Attribution CC BY 3.0 IGO;

[20] Stancu, S., Popescu, O.M. (2018), International Migration: The Analysis of economic Impact in the Globalization Context; Economic Computation and Economic Cybernetics Studies and Research; ASE Publishing; 52(4):79-94; [21] Tachiwou Aboudou, A.M. (2009),Causality Tests between Stock Market Development and Economic Growth in West African Monetary Union;

Economia. Seria Management,12(2):14-27;

[22] Tekin, R. B. (2012), Economic Growth, Exports and Foreign Direct Investment in Least Developed Countries: A Panel Granger Causality Analysis; Economic Modelling, 29(3): 868-878;

[23] https://www.statisticshowto.datasciencecentral.com/granger-causality/ [24] worldbank.org. 